\title{
Research on the Oretical Innovation and Design Method of the Integration of Highway and Toruism
}

\author{
Yang Xing $^{1 *}$, Yangzhi Sheng ${ }^{1}$ \\ ${ }^{1}$ Transport Planning and Research Institute, Ministry of Transport, China, Beijing
}

\begin{abstract}
Highway is an important carrier for the integration of transportation and tourism. At present, there are still some problems in the integration of highway transportation and tourism, such as unclear connotation, unclear thinking, inadequate understanding and incomplete measures. In order to better promote the integration development of Expressway and tourism $t$ solve the problems encountered in the practice of various places, the advantages and disadvantages of the integration of Expressway and tourism are analyzed on the basis of a comprehensive review of the current development situation and needs of tourism and transportation industry. According to the basic characteristics of expressway, this paper innovatively puts forward the basic connotation, main characteristics, main contents and construction significance of expressway traffic integration. According to the requirements of the integration and development of tourism and transportation, this paper probes into the point-axis theory, circle theory and tourism flow theory related to tourism and transportation, and puts forward the application value of each theory in the field of tourism and transportation. Under the guidance of relevant theories, the main ideas of highway traffic integration, the basic elements and key design points of highway traffic integration are put forward. Comparing with the traditional expressway, the paper puts forward the main points of the route design of the tourist expressway, the main points of the interchange design of the tourist expressway which is different from the traditional expressway kilometers, the three types of the service area of the tourist expressway, and the four innovative design modes of the tourist Expressway sightseeing and recreation area. Combining with the relevant theories of tourism flow, this paper innovatively puts forward the traffic volume forecasting method of tourism expressway. Finally, from the land, capital and construction mode, the paper puts forward the guarantee measures of highway traffic integration.
\end{abstract}

\section{Introduction}

At present, tourism has become the pillar industry of our country, tourism products and formats are more abundant, and the per capita travel expenses of tourists gradually increase. With the rapid rise of mass tourism and self driving tourism and the rapid promotion of the whole area tourism strategy, tourism highway, as an important starting point of transportation supporting the rapid development of tourism industry in China, has once again attracted great attention from all over the country, and various regions have launched a new wave of construction of tourism roads. In recent years, China's highway construction has made rapid development. While undertaking cross regional and large capacity rapid transportation, some expressways also play an important role in connecting important scenic spots and driving urban development, and have significant tourism functions. In today's "transportation and tourism integration, shared development", how to better adapt to the development requirements of the new era and the new situation, to better play the basic supporting role of tourism in the whole region, to better meet the driving and promoting role of industrial development, scenic spot development and poverty alleviation along the line, to better meet the growing needs of travelers, and to better achieve Sustainable development has become the focus of attention of builders.

\section{Background of Tourism Transportation Development}

With the advent of the era of mass tourism and the development of modern tourism, the tourism market has witnessed a blowout growth. According to the relevant data of the National Tourism Administration, in 2017, the number of tourists in China reached 5.0 billion, equivalent to 3.6 times per capita of 1.39 billion people ${ }^{[1]}$. Among them, the number of domestic tourists reached 5.0 billion, accounting for $97.4 \%$. In 2017 , the total national tourism consumption reached 5.40 trillion yuan, equivalent to 3885 yuan per capita spent on tourism. Tourism transportation is one of the three pillars of tourism industry. The rapid rise of tourism industry cannot do without the full support of transportation. It can be said that without modern transportation, there will be no modern tourism.

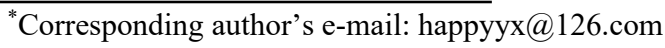


With the gradual completion of expressway network and the implementation of the policy of free passage of passenger cars on national expressways during holidays, self driving has become an important means of travel. As a means of travel transportation, highway accounts for more than $70 \%$ of the "whole area tourism" destinations, which is an important part of tourism transportation in the era of "mass tourism" and "global tourism". In 2017, self driving tourists accounted for more than $62.0 \%$ of the total number of domestic tourists, more than 3.1 billion, becoming a new growth point of the tourism industry ${ }^{[2]}$. High quality, diversified and personalized travel demands put forward higher requirements for the construction and service quality of tourist roads. All kinds of signs show that: tourism transportation, especially the tourism highway, has become the best focus and important starting point to give full play to the potential of tourism supply side, improve the level of tourism industry and promote the transformation and development of transportation industry.

\section{Connotation and characteristics of expressway traffic and tourism integration}

\subsection{Analysis on characteristics of expressway traffic and tourism integration}

\subsubsection{Advantage analysis}

Expressway has the following advantages in the following aspects: first, it can effectively shorten the time for tourists to arrive at scenic spots; second, the highway has the monopoly of natural tourist resources, which is the best carrier for gathering people and passenger flow (which can be called "large travel agency"); third, as the main artery of regional transportation, the expressway can effectively shorten the time for tourists to arrive at scenic spots; third, as the main artery of regional transportation, the highway can develop tourism resources along the line Fourthly, the service radius of scenic spots along the line can be significantly expanded by connecting scenic spots with expressways (practice has proved that the construction of expressway traffic network near tourist attractions can expand the radiation radius of scenic spots relying on highway transportation by $320-500 \mathrm{~km}^{[3]}$.

\subsubsection{Disadvantage analysis}

As a relatively closed travel space, expressway also has some defects and deficiencies in the development of transportation and tourism integration. For example, tourists have less travel experience with stop and go, limited close contact with scenic spots, low travel service quality of existing expressways, and lack of departmental linkage and cooperation mechanism.

\subsection{Basic connotation of expressway traffic and tourism integration}

At the present stage, the development of highway traffic and tourism integration is to give full play to the inherent advantages of the expressway, such as large service radius, concentrated passenger flow, rich regional landscape and tourism resources, and through the construction of a comprehensive and three-dimensional tourism transportation system, drive and activate the existing and potential scenic spots, radiate and serve the rural tourism development along the line, so that tourists can get more benefits Get a comfortable, comfortable and warm highquality travel experience.

\subsection{Main features of expressway traffic and tourism integration}

The main characteristics of expressway traffic and tourism integration are as follows:

Panoramic travel experience. For tourists, when driving on the highway, they will enjoy the beautiful natural scenery on the roadside, and can feel the rich local characteristic culture when visiting the service area, forming a panoramic travel experience.

All round tourism radiation drive. Through the connection and radiation of the expressway itself to the surrounding scenic spots and scenic spots, as well as the service of the auxiliary road parallel with the expressway to the surrounding scenic spots and scenic spots and the driving force to rural tourism, the comprehensive tourism radiation drive can be realized.

A full range of travel services. Along the highway, through the service area, sightseeing and recreation area, as well as the parallel auxiliary roads, the tourism industry chain integrating food, housing, transportation, tourism, shopping and entertainment is provided to provide a full range of travel services.

The whole process of tourism product planning. Starting from the whole process and all angles of pre planning, mid-term design and follow-up operation, the tourism product development and planning of the whole expressway line is carried out. Through the tourism products, strong tourism attraction is formed and more tourists are attracted.

Tourism innovation management from all perspectives. Through the joint creation of facilities along the highway and scenic spots, the revenue of scenic spots and expressway can be shared, and traffic management personnel and scenic spot managers can be integrated into a new perspective of tourism management mode.

\subsection{Main contents of expressway traffic and tourism integration}

According to the characteristics of tourism Expressway and the demand of tourism integration, tourism expressway can construct seven systems in the future, the specific structure is as follows: 
(1) Mainline system. It mainly refers to the main route of expressway, subgrade, pavement, bridge, culvert and tunnel itself.

(2) Hub system. It refers to the hub set up along the expressway to serve tourists. It includes interchange and service area. Node type (conversion with other expressways and national highways), service type (mainly serving scenic spots and tourists). It includes four types: node interchange, service interchange, sightseeing service area and scenic entrance service area.

(3) Landscape system. It refers to the theme of landscape features, the division of landscape sections and the creation and setting of landscape recreation facilities along the expressway according to the natural features and cultural characteristics.

(4) Auxiliary road system. The highway traffic and tourism integration should not only focus on the expressway itself, but also take on the responsibility of regional traffic and tourism integration together with the expressway, build the regional road network, jointly serve the development of scenic spots and promote the development of poverty alleviation along the line. Therefore, the auxiliary road system around the expressway has become an important part of the highway traffic and tourism integration.

(5) Slow moving system. Including walking system and bicycle system. It includes not only the bicycle lane set up around the auxiliary road combined with the actual demand and the characteristics of the scenic spot, but also the pedestrian system set up inside the expressway service area and around the sightseeing and recreation area.

(6) Boot system. There are many facilities along the tourism expressway. In view of the high speed of the highway itself, it is very important to do a good job of information prompt, guidance and instruction along the highway. Therefore, it is necessary to build a perfect guidance system around three aspects: basic travel of expressway, publicity of high-speed tourism image and implantation of tourism high-speed culture.

(7) Intelligent system. With information technology as a means, to meet the convenience of travel, efficient management, intelligent monitoring and other related technologies.

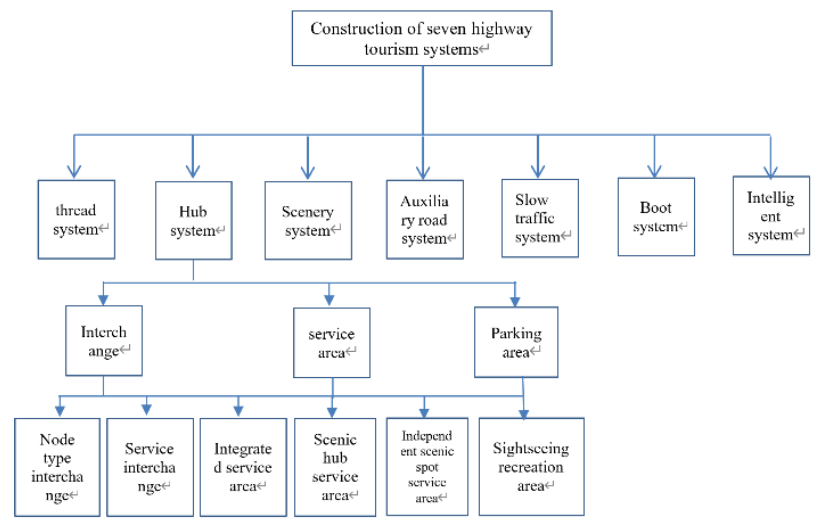

Figure 1. construction of seven major systems of tourism Expressway

\section{Research on innovation theory of expressway traffic and tourism integration}

\subsection{Point axis theory}

The point axis theory was first put forward in 1984 by Lu Daodao, a famous economic geographer in China, based on the central place theory of Chris Taylor, the spatial diffusion theory of hergelsdland and the growth pole theory of Perroux [4]. The point axis system theory is the basic theory of regional development, which can guide the corridor construction and radiation drive of tourism transportation. It has been widely used in China's land development and regional development and has a profound impact. It also has very important theoretical value and practical guiding significance for tourism transportation development ${ }^{[5]}$.

The theoretical application of point axis theory in tourism transportation mainly includes: first, play the radiation and driving role of landscape nodes on regional tourism; second, improving the accessibility of tourist attractions ${ }^{[6]}$.

\subsection{Circle theory}

Tourism circle theory is put forward on the basis of tourism spatial structure. The formation of tourism circle is the result of mutual cooperation and selection of tourism transportation space. The theoretical application of circle theory in tourism highway is mainly reflected in [7]: (1) tourism circle is a cooperative area with a certain geographical scope composed of tourism resources as the core, forming different levels of road landscape and recreational activities, radiating to the branch line or slowmoving system of tourism highway, with regional coherence; (2) the construction of tourism circle breaks the concept and rules of local departmentalism It can effectively enrich the content of tourism activities, expand the time capacity of tourism activities, and make the best economic benefits of tourism roads.

\subsection{Tourism Flow theory}

Tourism flow is a collection of one-way and two-way tourist flow, information flow, capital flow, material flow, energy flow and cultural flow between source and destination or between destinations. The narrow sense of tourism flow refers to tourist flow, which constitutes the core of tourism flow research. Tourism flow is a vector unit, which has the characteristics of fluid quality, flow, flow direction and velocity. The differences of intensity, distribution and spatial grade structure are related to the rational utilization of tourism infrastructure and tourism reception service facilities, and ultimately affect the economic, social and environmental benefits of tourism destinations. The basic model of spatial field effect of tourism flow can be divided into three elements: tourists, tourism nodes and tourism channels. According to the different levels of regional spatial structure, the research 
objects of the spatial field effect of tourism flow can be divided into three types: point, line and area, which have different research focus ${ }^{[8]}$.

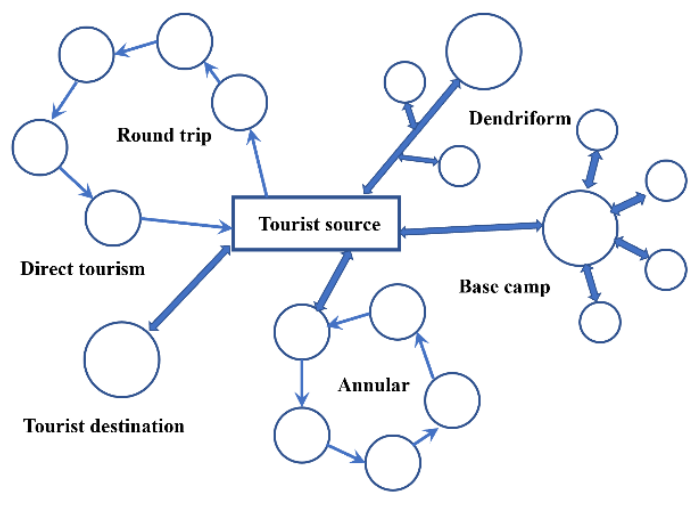

Figure 2. Space Behavior Patterns of Tourists ${ }^{[9]}{ }^{[10}$

The tourism gravity model based on Newton's law of gravitation proposed by J. crampon in 1966 is a classical model to measure the potential of tourism flow.

$$
T_{i j}=G \frac{P_{i} A_{j}}{D_{i j}^{b}}
$$

Where TIJ is the measurement of tourist flow between source $\mathrm{i}$ and destination $\mathrm{J}$; PI is the measurement of population size, wealth or travel tendency of source i; AJ is some measure of attraction of destination $\mathrm{J}$ to source $\mathrm{i}$; DIJ is the distance between source $\mathrm{i}$ and destination $\mathrm{J} ; \mathrm{G}$ and $\mathrm{b}$ are empirical coefficients ${ }^{[11]}{ }^{[12]}$.

In general, the continuous improvement of high-speed transportation system has broken through the traffic bottleneck of cities with weak location, and promoted the relative fairness of tourism flow distribution between cities $^{[13]}$

\section{Research on the design method of expressway traffic and tourism integration}

\subsection{Main ideas of expressway traffic and tourism integration}

Idea 1: big integration. That is to say, taking the highway as the medium, forming the radiation corridor, driving the development of tourism and industry around, making it become the radiation corridor of the region, and become the economic development axis and industrial driving belt.

Idea 2: small integration. That is to say, the highway itself is combined with tourism resources (such as important scenic spots) and cultural elements along the highway.

Idea 3: direct integration. In other words, expressway interchanges and service areas are directly set up in places with rich tourism resources or beautiful landscapes, so as to meet the tourists' demand for direct sightseeing and recreation.

Idea 4: indirect integration. That is to say, expressway construction connects and extends to the surrounding scenic spots through interchange and service area, which serves the purpose and function of indirect tourism development.

\subsection{Basic elements and key design points of expressway traffic and tourism integration}

For tourism expressway, there are some differences in route selection, interchange layout, service area location and sightseeing recreation area setting, which are shown in Table 1.

Table 1. Analysis of the basic path of the fusion of highway and tourism.

\begin{tabular}{|c|c|c|}
\hline Category & $\begin{array}{c}\text { Ordinary } \\
\text { Expressway }\end{array}$ & Tourism Expressway \\
\hline $\begin{array}{l}\text { Route } \\
\text { selection }\end{array}$ & $\begin{array}{c}\text { Short } \\
\text { mileage and } \\
\text { convenient } \\
\text { connection }\end{array}$ & $\begin{array}{l}\text { Close range without entering the } \\
\text { scene, connecting the main scenic } \\
\text { spots and scenic spots }\end{array}$ \\
\hline $\begin{array}{c}\text { Interchange } \\
\text { layout }\end{array}$ & $\begin{array}{l}\text { Meet the } \\
\text { requirement } \\
\text { s of rapid } \\
\text { and } \\
\text { convenient } \\
\text { travel of } \\
\text { towns along } \\
\text { the line }\end{array}$ & $\begin{array}{l}\text { (1) In order to serve the tourists of } \\
\text { scenic spots along the line } \\
\text { (2) Guide tourists to scenic spots, } \\
\text { scenic spots or special tourism } \\
\text { resources along the line }\end{array}$ \\
\hline $\begin{array}{c}\text { Site } \\
\text { selection of } \\
\text { service area }\end{array}$ & $\begin{array}{l}\text { The site } \\
\text { conditions } \\
\text { are satisfied } \\
\text { and the } \\
\text { spacing is } \\
\text { appropriate } \\
(50 \mathrm{~km})\end{array}$ & $\begin{array}{l}\text { (1) Emphasis on flexible setting, } \\
\text { area, scale, content can be flexible } \\
\text { (2) It can be unilateral or bilateral } \\
\text { (3) It can be viewed simply or } \\
\text { combined with the entrance of the } \\
\text { scenic spot } \\
\text { (4) Transport tourists to the } \\
\text { surrounding scenic spots to achieve } \\
\text { win-win situation of Expressway } \\
\text { and scenic spot } \\
\text { (5) It is built as a scenic spot }\end{array}$ \\
\hline $\begin{array}{l}\text { Setting of } \\
\text { sightseeing } \\
\text { and } \\
\text { Recreation } \\
\text { Area }\end{array}$ & $\begin{array}{l}\text { Basically } \\
\text { not } \\
\text { considered }\end{array}$ & $\begin{array}{l}\text { (1) It can be set up in the section } \\
\text { with rich landscape resources and } \\
\text { tourism resources } \\
\text { (2) Combining with the } \\
\text { development of local characteristic } \\
\text { towns and industries } \\
\text { (3) Combined with Rural } \\
\text { Revitalization and rural tourism } \\
\text { development } \\
\text { (4) Close connection with the } \\
\text { entrance of scenic spot } \\
\text { (5) Flexible setting according to } \\
\text { local conditions }\end{array}$ \\
\hline
\end{tabular}

\subsubsection{Key points of route design of tourism Expressway}

In the route selection and design of tourism expressway, the following design points should be taken into consideration.

Point 1: try to connect and connect the existing and mature scenic spots along the line; point 2: drive and activate the potential scenic spots; point 3 : reduce the interference to the core scenic spots according to the idea of close range without entering the scenery; point 4: implement the concept of green highway construction, adhere to the balance of filling and excavation, and strive to achieve "zero abandonment" and "less borrowing". 


\subsubsection{Key points of interchange design of tourism Expressway}

According to the design idea of tourism expressway, that is, the main starting point is no longer to serve the counties and towns and connect high-grade highways, but to make it more convenient for tourists to go to the main scenic spots, to meet the rapid access of tourists and to drive the development of scenic spots. At the same time, considering the land resource conservation, some service facilities (such as service area, sightseeing and recreation area, etc.) can be combined with the interchange.

\subsubsection{Design points of tourist expressway service area}

(1) Classification of service areas of tourism Expressway Combined with the distribution characteristics of scenic spots and tourism resources around the tourism expressway, and considering the convenience and driving of travel service for tourists, this paper innovatively divides the service area of tourism Expressway into three types: Scenic entrance expressway service area, theme expressway service area and rural integrated expressway service area.

(2) Design ideas and methods of tourist expressway service area at entrance of Scenic Area

This kind of service area mainly solves the problem that the expressway service area and the potential scenic spot are integrated and integrated. As the entrance and parking lot of the scenic spot, the original expressway service area can meet the basic service function of Expressway and the entrance parking function of scenic spot. Other recreational, scenic, entertainment and leisure activities are placed in the scenic area close to the expressway service area. A one-sided service area can be set up through simple intercommunication. In the future, it is proposed to build a scenic spot above a level.

(3) Design ideas and methods of theme tourism expressway service area

Focusing on the display of local characteristic culture, industry and economy, the theme and characteristic tourism expressway service area will be built, and the expressway service area will be built into a tourist destination, and a comprehensive tourism transportation network of "fast forward and slow travel" will be gradually constructed [14]. Such as "high-speed + automobile exhibition and sales industry", "high-speed + convalescent vacation", "high-speed + local specialty trade", "high-speed + flower tourism", "high-speed + tea culture", "high-speed + love wedding" and "high-speed + leisure vacation" are the themes of the service area.

(4) Design ideas and methods of service area of rural integrated tourism Expressway

It mainly refers to the combination of expressway service area and rural tourism resort along the line. Through the establishment of open service area, tourists can enter the surrounding rural tourism resort through the service area, carry out different kinds of sightseeing activities and participate in the daily life of the people along the line, so as to realize the purpose of promoting rural poverty alleviation and tourism development and better promote the rural areas Civilization construction.

\subsubsection{Design points of sightseeing and recreation area of tourism Expressway}

Combined with the setting idea and location of sightseeing and recreation area, it is divided into four categories. The specific ideas are as follows:

Idea 1: through the combination of sightseeing and recreation area and local unique tourism resources, show regional customs and characteristics. That is, by setting up a sightseeing and recreation area in the characteristic tourism resources, tourists will be attracted here, and the most beautiful scenery and scenery will be displayed to tourists.

Idea 2: the new gate of the scenic area is connected with the sightseeing and recreation area, so as to realize the seeing off and door-to-door of the expressway. A new "door-to-door travel agency" can be set up along the expressway along the scenic area. Set up a parking lot shared by the highway and the scenic spot in the sightseeing and recreation area (free use within half an hour according to the public welfare attribute of the highway, and charge management according to the parking lot of the scenic spot after more than half an hour). Tourists who enter the scenic spot through the expressway can enjoy the ticket discount, and the additional income obtained by the scenic spot will be shared with the transportation department in the future.

Idea 3: connect with local characteristic towns through sightseeing and recreation area. In the sightseeing and recreation area set along the expressway, tourists can transfer to other transportation modes (such as battery cars, bicycles, etc.) to the surrounding scenic spots and scenic spots, including the surrounding characteristic towns, so as to realize the radiation and drive of the expressway to the surrounding resources ${ }^{[15]}$.

Idea 4: connect with local characteristic industries through sightseeing and recreation area. In the sightseeing and recreation area set along the expressway, tourists can go to the surrounding characteristic industrial park and agricultural products exhibition and marketing points by transferring to other transportation modes (such as battery cars, bicycles, etc.), such as going to the characteristic tea houses along the line, participating in various activities of tea appreciation, tea tasting, tea picking and tea making, so as to drive the local characteristic industries and extend the industrial chain ${ }^{[16]}$.

\subsubsection{Traffic volume forecast method of tourism Expressway}

(1) Fitting and forecasting according to the number of tourists of tourist attractions recorded over the years ${ }^{[17]}$.

The number of tourists in tourist attractions is divided into international tourists and domestic tourists, so the arrival of tourists in tourist attractions is in gradient growth. Therefore, the three trend curve prediction model, one of the time series methods, is used to predict and fit the number of tourists in the past few years. The prediction 
model of cubic polynomial trend curve can be expressed as follows:

$$
\mathrm{P}=\mathrm{b}_{0}+\mathrm{b}_{1} * \mathrm{t}+\mathrm{b}_{2} * \mathrm{t}^{2}+\mathrm{b}_{3} * \mathrm{t}^{3}+\ldots \ldots \ldots \ldots \ldots
$$

Where: $\mathrm{P}$ — Tourist forecast

$$
\mathrm{T} \text { - Time value }
$$

determined

$$
\mathrm{b}_{0}, \mathrm{~b}_{1}, \mathrm{~b}_{2}, \mathrm{~b}_{3}-\mathrm{The} \text { required parameters are }
$$

This model is solved by the least square method.

(2) Investigate the passenger traffic situation of tourist attractions

In this step, it is necessary to investigate the passenger traffic around the tourist attractions. Generally, there will be several roads connecting the tourist attractions, so it is necessary to investigate the passenger traffic conditions at the same time, and the survey period should not be less than 24 hours. The survey includes the classification of passenger vehicles, passenger cars, the number of seats per vehicle and the load factor of passenger vehicles.

(3) On the basis of the number of tourists, the traffic demand of tourism highway is predicted

On the basis of step (1) and step (2), it is necessary to establish a conversion model to forecast the traffic demand of tourism highway. The representation of this transformation model is as follows:

$$
\begin{aligned}
Q^{\prime}= & \left(P_{\text {tot }} \cdot \mathrm{a}_{1} \cdot \mathrm{PCE}_{1}\right) /\left(365 \cdot \mathrm{N}_{\mathrm{S} 1} \cdot \mathrm{L}_{1}\right)+ \\
& \left(\mathrm{P}_{\text {tot }} \bullet \mathrm{a}_{2} \cdot \mathrm{PCE}_{2}\right) /\left(365 \cdot \mathrm{N}_{\mathrm{S} 2} \cdot \mathrm{L}_{2}\right)
\end{aligned}
$$

Where: Q' F Forecast value of travel highway traffic demand;

$\mathrm{a}_{1}, \mathrm{a}_{2}-$ Share rate of passenger cars and buses; buses;

$\mathrm{PCE}_{1}, \mathrm{PCE}_{2}-$ Equal value of passenger cars and

$\mathrm{N}_{\mathrm{S} 1}, \mathrm{~N}_{\mathrm{S} 2}-$ Number of seats in passenger cars and buses;

$\mathrm{L}_{1}, \mathrm{~L}_{2}-$ Vehicle load factor of passenger cars and buses.

(4) Comparison and correction of forecast results with accurate traffic survey data

In step (4), the relative error between the predicted value and the real value can be determined by comparing the predicted value with the survey value of the travel highway traffic demand. If the predicted value can not meet the requirements, the model hypothesis is fed back and modified.

\subsection{Expected effect of expressway traffic and tourism integration}

Through the construction of highway traffic and tourism integration, the expected effects in the following aspects can be achieved.

One is the diversification of service methods. Through the deep integration of highway and tourism in the new era, as well as the development of new technology and new business forms, the transformation from manual sales in the former expressway service area to online selfservice sales can be realized, and "mobile counters" can be created.
The second is the characteristic of service content. Stimulated and driven by the development of tourism in the whole region, and led by the growing diversified and personalized needs of the people, the related commodities in the expressway service area will change from the fixed products in the past to the characteristic and personalized customization (booking in advance and picking up goods at fixed points), making the Expressway a "mobile stage" for the display of specialty products and commodities along the line ${ }^{[18]}$.

The third is the expansion of service scope. In the past, the highway service facilities only rely on the service area and parking area along the line, providing point service. In addition to the traditional service area and the newly added sightseeing and recreation area, the tourism Expressway under the perspective of traffic and tourism integration realizes the combination of service area and scenic spot. The combination of sightseeing recreation area and rural tourism makes the scope of service expand from point to area, making the highway become a "flowing scenery".

Fourth, the diversification of service supply. As the service mode of tourism expressway has realized the expansion from point service to area service, it has also realized the transformation from traffic service to social service, which has made the traffic culture spread, developed and expanded on the expressway, and created a "flowing culture".

Footnotes should be avoided whenever possible. If required they should be used only for brief notes that do not fit conveniently into the text.

\section{Guarantee measures for high speed traffic and tourism integration}

\subsection{Land policy guarantee}

Compared with general expressways, tourism expressways expand the original basic service functions and increase the demand for tourism, recreation, leisure and shopping. Therefore, it is necessary to increase the original service area and add new sightseeing and recreation areas. How to solve the increase of land demand caused by functional expansion is a prominent problem in the construction of tourism expressway Something's wrong. This paper puts forward the following solutions: first, the new land is solved by bidding, auction and listing in the secondary market of the government; second, the new land is solved by using the original spoil ground (temporary land) and then by longterm leasing; third, the problem of land needed for additional tourism functions can be solved by $\mathrm{CO}$ building with existing scenic spots; fourth, all the land for service areas can be considered Fifth, when land survey is carried out after the completion and acceptance of expressway, the surplus land index can be used for the construction of sightseeing recreation area. 


\subsection{Exploration of financing mode}

Like the land demand, the new tourism function of the tourism expressway needs to increase additional investment. For the financing mode and channels of tourism expressway, this paper suggests the following: first, using government support financing, mainly for tourism treasury bond projects, fund support, ecological protection projects, cultural relics protection projects, cultural projects, etc.; second, through leasing financing, such as asset leasing, land leasing, facilities leasing, etc.; third, commercial credit financing, including advance fund construction, ecological protection projects, cultural relics protection projects, etc Ticket deduction, pre-sale and pre-sale, time right financing, etc.; fourth, property rights financing, including property rights of hotels and shops ${ }^{[19]}$.

\subsection{Analysis of construction mode}

Because the tourism expressway is different from the traditional expressway, its service area increase, recreation facilities increase, service facilities function expansion, integration with tourism industry and other aspects, need to break the traditional construction and management ideas, according to the new requirements of the new situation, adopt innovative construction and management ideas. Firstly, it is suggested that the government should take the lead to establish the linkage and coordination mechanism among transportation, forestry, land and land, tourism, towns along the line, and scenic spot management committee; secondly, it is suggested to provide relevant policy and financial support in the project initiation, approval and implementation according to the principle of "special treatment, classified examination and approval, and independent approval"; thirdly, it is suggested that the development and construction of new scenic spots along the line and auxiliary roads Fourth, it is suggested to adopt the phased implementation mode to do a good job in the infrastructure construction within the scope of the expressway in the first stage, and then to expand the tourism function in combination with the development of rural tourism.

\section{Epilogue}

In China, the integrated development of transportation and tourism is in full swing all over the country. As the core force of China's road network, expressway is bound to play an important role in supporting the development of tourism in the whole region. It is of great significance to analyze and study the mode and thinking of highway traffic and tourism integration, and establish and improve the path and guarantee system of highway traffic and tourism integration, which is of great significance for further promoting and promoting the deep integration of highway and tourism, and will become an important starting point in the transformation period of highway construction.

\section{References}

1.Annual Report on China's Domestic Tourism Development 2018

2. https://baike.so.com/doc/650689-688804.html;

3. OU Yue-nan, XIE Guang-qiu. Feasibility of Expressway Construction and Tourism Economy Development: Academic Edition, 2005 (02): 60-62;

4. LU Xiao-bo, CHEN Xiao-ying. Study on the Strategy of Regional Tourism Collaborative Development in Northeast China Based on Point-Axis Theory[J]. Northeast Asia Economic Research, 2018 (06): 78-92;

5. LU Da-dao. About "the formation mechanism analysis of the point-axis spatial structure system"[J]. Geographical Science, 2002, 22 (01): 1-6;

6. LU Da-dao. On the Best Structure and the Best Development of the Area-Retrospective and reanalysis of "point-axis"system and "T" structure[J]. Journal of Geography, 2001, 56 (02): 127-135;

7. GAO JIE, SUN Xiao-long. Study on Space Structure and Optimization of Summer Tourism Based on Circle Theory-Take Guiyang as an example[J], Journal of He Bei North University (Social Science Edition), 2016 (05): 58-63;

8. YUAN Yu-jie. Study on Tourism Flow and Construction of Tourism "Double Flow" System[J], Tourism Science, 2015 (01): 6-11;

9. UANG Jinhuo, WU Bi-hu. Model and Optimization of Spatial Structure of Regional Tourism SystemTake Xi'an as an example[J], Advances in geographic science, 2005, 24(1): 116-125;

10. Christaller W.Some considerations of tourism location in Europe: The peripheral region-underdeveloped countries-recreation areas[J], Papers in Regional Science, 1964, 12(1): 95-105;

11. Weaver D B. Model of urban tourism for small Caribbean islands[J], Geographical Review, 1993, (2): 134-140;

12. YANG Xin-jun, NIU Dong, WU Bi-hu. Spatial Model of Tourism Behavior and Its Evaluation[J], Economic Geography, 2000(4): 105-108,117;

13. LU Lin. Study on spatial behavior of tourists in mountain Scenic area-On the Comparison between Huangshan and Yellowstone Park[J], Journal of Geography, 1996(4): 315-321;

14. HOU Zhi-qiang. Empirical Analysis of the Effect of Traffic Infrastructure on Regional Tourism Economic Growth-Spatial Measurement Model Based on the Data of China Provincial Panel[J]. Macroeconomic research, 2018(06):118-132;

15. LI Ru-you, HUANG Chang-zhou. Study on the Impact of Chinese Transportation Infrastructure on Regional Tourism Development-Evidence based on threshold regression model[J]. Tourism Science,2015(02): 1-13;

16. ZHANG Guang-hai, ZHAO Jin-jin. Spatial Measurement of the Impact of China's Transportation Infrastructure on Regional Tourism Economic 
Development[J]. Economic Management, 2015(07): 116-126;

17. Research on the Integration of Regional Tourism Resources and Highway Network (2nd Edition[M]), People's Transport Publishing Co., Ltd. June 2018, 2nd edition;

18. WANG Cheng-ping. Rational Thinking on the Integration and Development of Highway Traffic and Tourism[J], Scientific Advice (Technology Management), 2017(09): 116-126;

19. ZHOU Yong, FU Hang. Discussion on the Idea of Highway Traffic and Tourism Integration Construction[J], Research on urban construction theory (electronic version), 2017(34): 116-126. 